\title{
Article \\ Features of the Chemical Interaction of 2-Furaldehyde and 1,3,5-Trihydroxybenzene in an Alkaline Medium to Obtain a Plasticizing Additive
}

\author{
Valentina Anatolyevna Poluektova (D), Natalia Igorevna Cherkashina *, Sergey Aleksandrovich Starchenko \\ and Dmitriy Sergeevich Romanyuk
}

\author{
Department of Theoretical and Applied Chemistry, Belgorod State Technological University Named after V.G. \\ Shukhov, 308012 Belgorod, Russia; val.po@bk.ru (V.A.P.); sereja650@gmail.com (S.A.S.); \\ romanyuk.dmitrij.98@bk.ru (D.S.R.) \\ * Correspondence: cherkashina.ni@bstu.ru
}

\section{check for}

updates

Citation: Poluektova, V.A.;

Cherkashina, N.I.; Starchenko, S.A.;

Romanyuk, D.S. Features of the

Chemical Interaction of

2-Furaldehyde and 1,3,5-

Trihydroxybenzene in an Alkaline

Medium to Obtain a Plasticizing

Additive. ChemEngineering 2021, 5, 84.

https://doi.org/10.3390/

chemengineering5040084

Academic Editors: Alírio E.

Rodrigues and Andrew S. Paluch

Received: 29 October 2021

Accepted: 3 December 2021

Published: 8 December 2021

Publisher's Note: MDPI stays neutral with regard to jurisdictional claims in published maps and institutional affiliations.

Copyright: (c) 2021 by the authors. Licensee MDPI, Basel, Switzerland. This article is an open access article distributed under the terms and conditions of the Creative Commons Attribution (CC BY) license (https:/ / creativecommons.org/licenses/by/ $4.0 /)$.

\begin{abstract}
The paper presents data on the study of the polycondensation of 2-furaldehyde and 1,3,5trihydroxybenzene in an alkaline medium to obtain a plasticizing additive. Results are presented on the study of the products of the separate interaction of 1,3,5-trioxybenzene and 2-furaldehyde with $\mathrm{NaOH}$, and the joint polycondensation of 1,3,5-trioxybenzene with 2-furaldehyde with $\mathrm{NaOH}$ by UV spectroscopy. The structure of the product of the interaction of 1,3,5-trioxybenzene with 2-furaldehyde in an alkaline medium was studied by IR spectroscopy. Stronger C-H bonds appear in the IR spectrum and stretching vibrations of the $\mathrm{C}=\mathrm{O}$ group are not observed, which confirms the production of a new compound. The optimal dosage of the developed plasticizing additive has been established as $0.3 \%$ of the cement mass (calculated on dry matter). The developed plasticizing additive can significantly reduce the water-cement ratio while maintaining the strength characteristics of cement compositions. In addition, when using the additive, the strength characteristics are significantly increased with a reduced water-cement ratio.
\end{abstract}

Keywords: UV spectroscopy; IR spectroscopy; superplasticizer; cement composition; water-cement ratio

\section{Introduction}

The use of chemical additives in building materials science makes it possible to improve the physical and mechanical characteristics of materials, and to simplify the technological process of their production [1-3]. Particular attention has been paid to additives for cement products [4-6]. The introduction of plasticizing additives allows you to regulate the rheological properties of the cement mixture, reduce the water-cement ratio, and ultimately leads to an increase in the mechanical properties of the concrete, or a decrease in its cost, by reducing the amount of cement in the composite formulations without reducing the physical and mechanical properties of the finished products [7-9].

The improvement of the technology for obtaining new self-compacting concrete (SCC) with improved rheotechnological and increased strength characteristics is continuously associated with the development of new plasticizing and superplasticizing additives. At the moment, there are a huge number of different superplasticizers available for cement systems [10-12].

$\mathrm{Wu}$ et al. [13] showed a positive effect of the use of a superplasticizer based on naphthalene and polycarboxylic acid. In their study, Wu et al. introduced a naphthalenebased superplasticizer in an amount of 0.8 to $2.0 \mathrm{wt} . \%$ and a superplasticizer based on polycarboxylic acid, also in an amount of 0.8 to $2.0 \mathrm{wt} \%$, in sulfoaluminate cement. A significant increase in the start and end of the setting of the cement was found.

Coppola et al. [14] developed a new phosphonate-based superplasticizer using an amino-methane-phosphonic polymer. The developed superplasticizer showed better char- 
acteristics in terms of reducing the water-cement ratio and maintaining workability compared to additives based on naphthalenesulfonate.

Plasticizers can be classified according to the mechanism of action on cement systems. The earliest plasticizers acted on cement systems through the effect of electrostatic repulsion of the cement particles. These were superplasticizers based on naphthalene-formaldehyde polycondensates [15], based on melamine-formaldehyde condensates [16], and based on lignosulfonates [17]. Such plasticizers have a minimal plasticizing effect. The new generation plasticizers work according to a completely different principle and, in terms of efficiency, they can already be classified as hyperplasticizers. Hyperplasticizers are produced based on polyacrylates $[18,19]$ and polycarboxylates $[20,21]$. Their mechanism of action on cement slurries is due to the predominant steric effect [22]. Much research has been devoted to the creation of superplasticizers and hyperplasticizers based on polycarboxylates [23-25].

Zhu et al. [26] established the possibility of synthesizing a modifier based on carboxylate and citric acid. Akhlaghi et al. [27] established the possibility of synthesizing a superplasticizer based on polycarboxylate and acrylic acid. They selected two co-monomers (i) 2-acrylamido-2-methylpropane sulfonic acid (AMPS) and (ii) vinylphosphonic acid (VPA) to be incorporated into the acrylic acid (AA) backbone of the PCEs. By adding $0.4 \%$ of the optimized superplasticizer, a $90 \%$ increase in flow was achieved.

Another promising direction is the creation of a superplasticizer based on furfural (2furancarbaldehyde). Furfural is a heterocyclic aldehyde of the furan series (2-furaldehyde). Furfural is obtained by acid-catalytic conversion of pentose carbohydrates, in particular, agricultural waste of herbaceous plants [28-30]. Due to this, furfural-based superplasticizers will have a much lower cost compared to traditional superplasticizers.

This work presents data on the synthesis of a plasticizing additive based on 2furaldehyde and 1,3,5-trihydroxybenzene, including the study of the chemistry of the reaction between the components, as well as data on the effect of the plasticizing additive on cement compositions.

\section{Materials and Methods}

\subsection{Materials}

The following components were used as reagents for the synthesis of a plasticizing additive ( $20 \%$ aqueous solution of 1,3,5-trihydroxybenzene-2-furaldehyde oligomer):

- $\quad$ phloroglucinol (1,3,5-trioxybenzene); manufactured by Panreac AppliChem. Density $1.46 \mathrm{~g} / \mathrm{cm}^{3}$.

- $\quad$ furfural (2-furaldehyde); manufacturer by Sigma-Aldrich (Saint Louis, MO, USA).

Density $1.16 \mathrm{~g} / \mathrm{cm}^{3}$; the content of the basic substance is not less than $99.3 \%$.

- $\quad$ sodium hydroxide $(\mathrm{NaOH})$; the content of the main substance is not less than $98 \%$. Manufactured by Panreac AppliChem.

The chemical formulae of the substances used to synthesize the superplasticizer are shown in Figure 1.<smiles>Oc1cc(O)cc(O)c1</smiles>

(a)<smiles>O=Cc1ccco1</smiles>

(b)

Figure 1. Structural formula: (a) 1,3,5-trioxybenzene; (b) 2-furaldehyde.

Determination of the plasticizing ability of the additive was based on Portland cement grade CEM I 42.5. The specific surface area of the Portland cement was $250 \pm 10 \mathrm{~m}^{2} / \mathrm{kg}$. 
The synthesis of the superplasticizer proceeded as follows: $2 \mathrm{~cm}^{3}$ of a $30 \% \mathrm{NaOH}$ solution was introduced into a round-bottom flask with a portion of 1,3,5-trihydroxybenzene weighing $1.22 \mathrm{~g}$, after which $9.4 \mathrm{~cm}^{3}$ of distilled water was poured into the mixture while stirring. The mixture was heated in a thermostat to a temperature of $70^{\circ} \mathrm{C}$ using a water heat carrier. This temperature is necessary for the reaction to proceed according to the data of previous studies [31].

To assess the effect of the rate of addition of the condensing agent (2-furaldehyde), two flasks with the same composition were prepared. After the temperature of the mixture reached $70{ }^{\circ} \mathrm{C}, 1 \mathrm{~g}$ of 2-furaldehyde was immediately introduced into the first flask, and the same mass of 2-furaldehyde was introduced into the second flask but only at a rate of $0.05 \mathrm{~mL} / \mathrm{min}$. Both mixtures were thermostatically controlled while stirring at a speed of $300 \mathrm{rpm}$ for $90 \mathrm{~min}$. After this time, the flasks with condensation products were cooled to room temperature.

\subsection{Research Methods}

The chemical structure of the starting monomers was investigated by spectroscopy using a Specord 200 plus spectrophotometer (manufactured by Analytik Jena AG, Jena, Germany). The UV spectra of the synthesis products were also used to study the chemical structure of the oligomers obtained (under various conditions). For refraction of radiation into the spectrum, a monochromator with a concave silver holographic grating was used, deuterium and halogen lamps were used as radiation sources, and an ultra-precise photodiode was used as an analyzer. For spectrometric studies, the solutions were prepared as follows: $0.1 \mathrm{~cm}^{3}$ of the synthesized compound was placed in a volumetric flask with a capacity of $250 \mathrm{~cm}^{3}$, dissolved in distilled water, and the volume of the solution was brought up to the mark. Then $20 \mathrm{~cm}^{3}$ of the finished solution was transferred into a volumetric flask with a capacity of $100 \mathrm{~cm}^{3}$, dissolved in purified water, and the volume of the solution was brought up to the mark. The UV spectra of the prepared solutions were recorded in the range from 200 to $700 \mathrm{~nm}$; distilled water was used as a reference solution. To record the UV spectra of the starting monomers, we used their aqueous solutions prepared as follows: $10 \mathrm{~cm}^{3}$ of distilled water was added to a sample weighing $2 \mathrm{~g}$.

The acquisition of IR spectra was carried out on a VERTEX 70 Fourier-IR spectrometer (manufactured by Bruker Optik GmbH, Ettlingen, Germany) at the Center for High Technologies of BSTU named after V.G. Shukhov. For preparation of the studied samples, especially pure potassium bromide, which is absolutely transparent to IR radiation, was used. The test sample was mixed with potassium bromide, thoroughly ground, and the disks were pressed under a pressure of 7 tons prior to recording their IR spectra. The IR spectra of the investigated substances were recorded in the range from 400 to $3900 \mathrm{~cm}^{-1}$.

${ }^{1} \mathrm{H}-\mathrm{NMR}$ spectra were obtained on a TESLA BS 476A spectrometer with an operating frequency of $60 \mathrm{MHz}$ (manufactured by Tesla, Czech Republic).

High-performance liquid chromatography (HPLC) analysis was used to determine the reaction products. Columns SEPARON SC-X C-18 were used. A RIDK 101 differential refractometer was used as a detector. Bidistilled water served as the eluent.

The molecular weight of the oligomers was determined by the cryoscopic method (Rast method) using a Beckman apparatus. The molecular weight was estimated by lowering the freezing point of a solution of the oligomer in dimethyl sulfoxide when compared with the freezing point of a pure solvent according to Formula (1):

$$
M=\frac{K \cdot g_{2} \cdot 1000}{g_{1} \cdot \Delta T}
$$

where $g_{1}$ is the mass of dimethyl sulfoxide, $g$; $g_{2}$ is the mass of the oligomer, $g ; K$-cryoscopic constant for dimethyl sulfoxide, $K=4.7 ; \Delta T$ is the freezing temperature difference.

The percent yield of the reaction was calculated by the Formula (2):

$$
\% \text { Yield }=\frac{\text { Actual Yield }}{\text { Theoretical Yield }} \cdot 100 \%
$$


The ultimate compressive strength (MPa) of plasticized and unplasticized cement compositions was determined on $2 \times 2 \times 2 \mathrm{~cm}$ cubes. The specimens under study gained strength for 28 days. The samples were tested on a PSU-50 laboratory hydraulic press. The maximum pressure generated by the hydraulic press is 50 tons.

\section{Results and Discussion}

3.1. Study of the Products of the Interaction of 1,3,5-Trioxybenzene and 2-Furaldehyde with $\mathrm{NaOH}$ by UV Spectroscopy

From the literature [32] it is known that 2-furaldehyde enters into a disproportionation reaction in an alkaline medium according to the Cannizzaro reaction (Figure 2.) with the formation of two reaction products, sodium salt of 2-furancarboxylic acid and 2-furyl methyl alcohol.

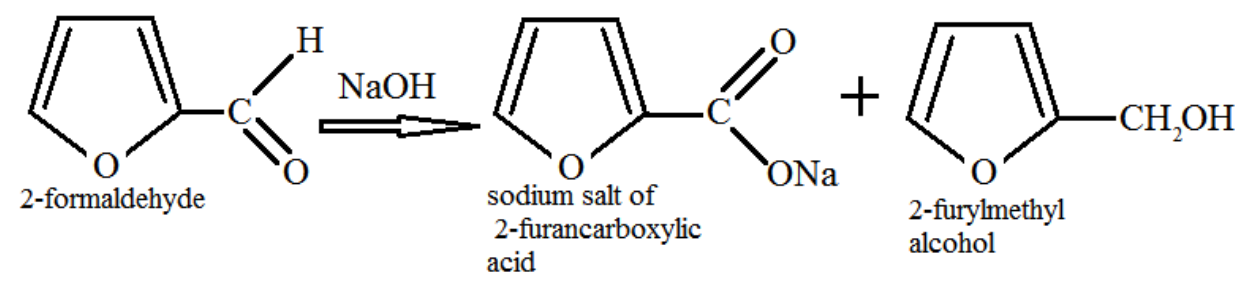

Figure 2. Disproportionation reaction of 2-furaldehyde (Cannizzaro reaction).

To establish the features of the chemical reaction (condensation) between 2-furaldehyde and 1,3,5-trihydroxybenzene in an alkaline medium, we first studied the interaction of each component (monomer) with $\mathrm{NaOH}$. The method of UV spectroscopy was used to record changes in the absorption maxima characteristic of monomers during their chemical interaction with alkali, which made it possible to determine the chemistry of the reaction. Figure 3 shows the initial and UV spectrum of the interaction of 1,3,5-trihydroxybenzene with $\mathrm{NaOH}$ at $70{ }^{\circ} \mathrm{C}$. The solution was stirred for $25 \mathrm{~min}$ at $70{ }^{\circ} \mathrm{C}$ and afterwards the solution was kept at room temperature for $24 \mathrm{~h}$.

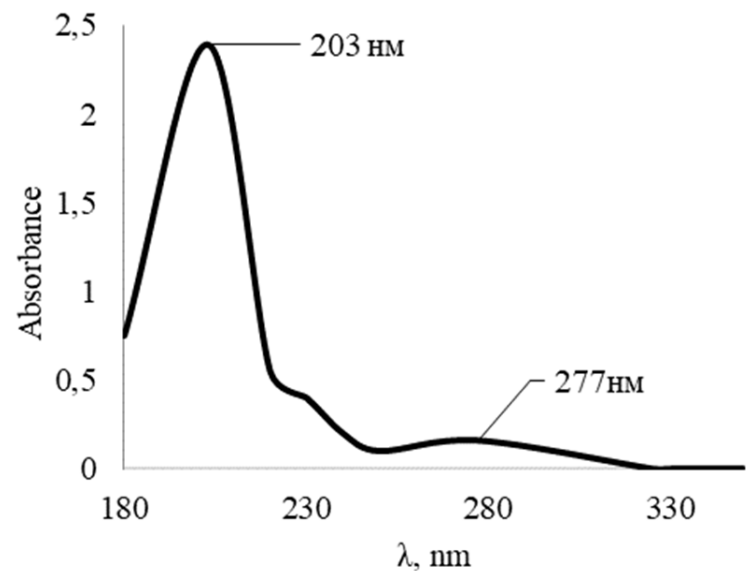

(a)

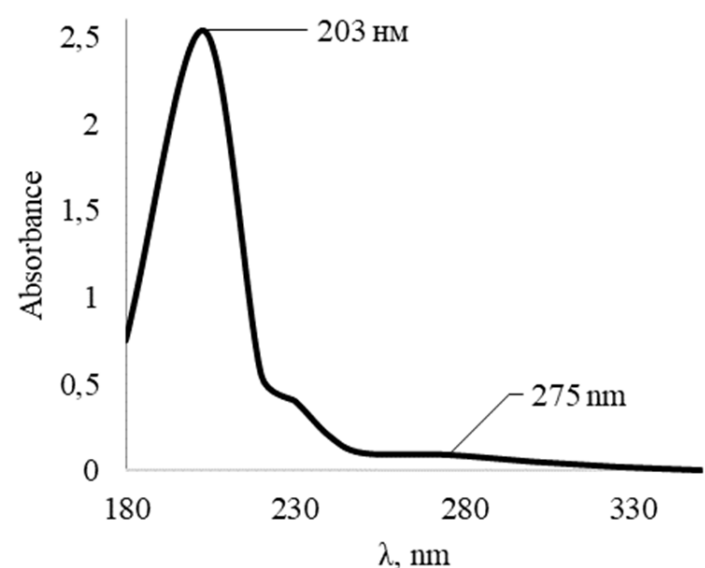

(b)

Figure 3. UV spectra of 1,3,5-trihydroxybenzene: (a) initial; (b) after interaction with $\mathrm{NaOH}$ at a temperature of $70{ }^{\circ} \mathrm{C}$ and holding for $24 \mathrm{~h}$.

Analysis of the UV spectra presented in Figure 3 showed that both spectra exhibit absorption maxima in the region of $203 \mathrm{~nm}$, characteristic of 1,3,5-trihydroxybenzene. A shoulder is also observed in the region from 213 to $245 \mathrm{~nm}$ and an absorption maximum in 
the region of $276 \mathrm{~nm}$. The results obtained indicate that 1,3,5-trihydroxybenzene does not react with $\mathrm{NaOH}$.

The stability of the solution does not change. However, a change in the color of the solution was noticed upon the addition of $\mathrm{NaOH}$; at first the solution had a light orange color, and after holding for $24 \mathrm{~h}$ it changed to a brown color. Perhaps the color change was due to the fact that $\mathrm{NaOH}$ improves the dissociation of 1,3,5-trihydroxybenzene molecules in water.

Figure 4 shows the UV spectrum of the control solution (2-furaldehyde aqueous solution) and the $\mathrm{UV}$ spectrum of the interaction of 2-furaldehyde with $\mathrm{NaOH}$ at $70{ }^{\circ} \mathrm{C}$ in the wavelength range from 190 to $500 \mathrm{~nm}$. As in the previous experiment, the solution was stirred for $25 \mathrm{~min}$ at $70^{\circ} \mathrm{C}$, and afterwards, the solution was kept at room temperature for $24 \mathrm{~h}$. In the control 2-furaldehyde aqueous solution, phase separation was observed where the bottom layer was 2-furaldehyde. No phase separation was observed in the solution with $\mathrm{NaOH}$. The formation of a homogeneous solution of dark brown color was observed in which a faint smell of 2-furaldehyde was detected. The UV spectrum of the control solution (Figure $4 \mathrm{a}$ ) and the solution with $\mathrm{NaOH}$ (Figure $4 \mathrm{~b}$ ) show an absorption maximum at $277 \mathrm{~nm}$.

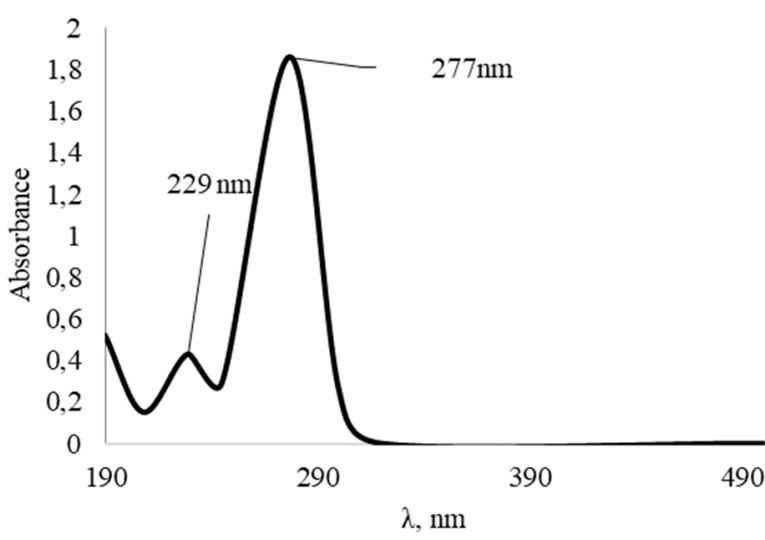

(a)

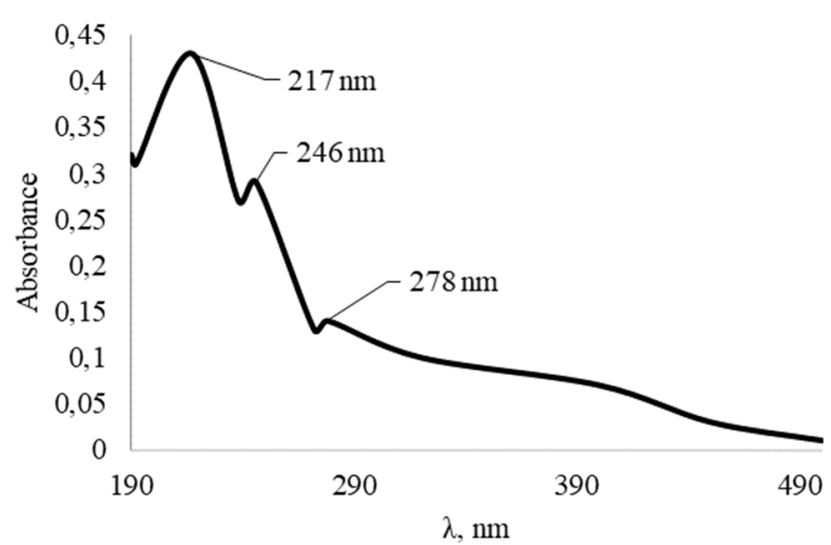

(b)

Figure 4. UV spectra of 2-furaldehyde: (a) control solution; (b) interaction with $\mathrm{NaOH}$.

In the UV spectrum of the interaction of 2-furaldehyde with $\mathrm{NaOH}$, new absorption maxima appear at 217 and $246 \mathrm{~nm}$ compared to the control solution, and the absorption maximum at $229 \mathrm{~nm}$ disappears. You can also notice that there is a decrease in optical density at a wavelength of $277 \mathrm{~nm}$ by three times compared with the control solution of the monomer.

Thus, based on the obtained UV spectroscopic data, it was found that 2-furaldehyde reacts with $\mathrm{NaOH}$ to form two products. It is known from the literature that the characteristic absorption maximum at a wavelength of $245 \mathrm{~nm}$ corresponds to 2-furancarboxylic acid and its salt, and the characteristic absorption maximum at a wavelength of $216 \mathrm{~nm}$ corresponds to 2-furyl methyl alcohol [33].

\subsection{Study of the Product of the Interaction of 1,3,5-Trioxybenzene with 2-Furaldehyde in an} Alkaline Medium by UV Spectroscopy

Since 2-furaldehyde undergoes disproportionation in an alkaline medium with the formation of two products, this reaction can interfere with the condensation reaction between 2-furaldehyde and 1,3,5-trihydroxybenzene in an alkaline medium. To establish the optimal method for the synthesis of a plasticizing additive based on 2-furaldehyde and 1,3,5-trihydroxybenzene, two parallel oligomer syntheses were carried out with different methods of adding the condensing agent. In the first solution, 2-furaldehyde was immedi- 
ately introduced, and in the second, the same mass of 2-furaldehyde was added but only at a rate of $0.05 \mathrm{~mL} / \mathrm{min}$.

The UV spectrum of the first solution (Figure 5a), where the addition of the condensing agent was instantaneous, shows absorption maxima at 215 and $279 \mathrm{~nm}$, which are characteristic of 2-furylmethyl alcohol and 2-furaldehyde, respectively. This suggests that the condensing agent did not fully enter into the condensation reaction with 1,3,5trihydroxybenzene, and began to partially disproportionate with the formation of 2-furyl methyl alcohol. Additionally, on the UV spectrum, there is no absorption maximum characteristic of 2-furancarboxylic acid. This suggests that 2-furancarboxylic acid reacted with 1,3,5-trihydroxybenzene.

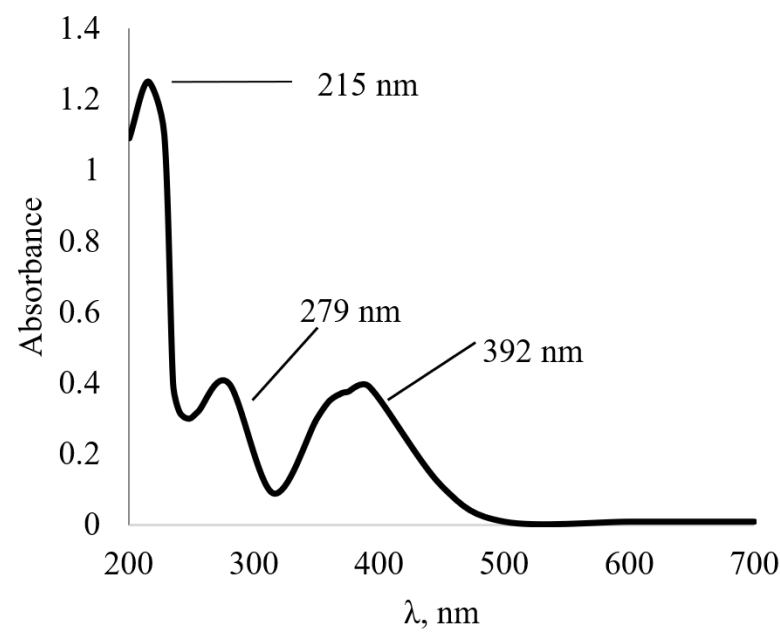

(a)

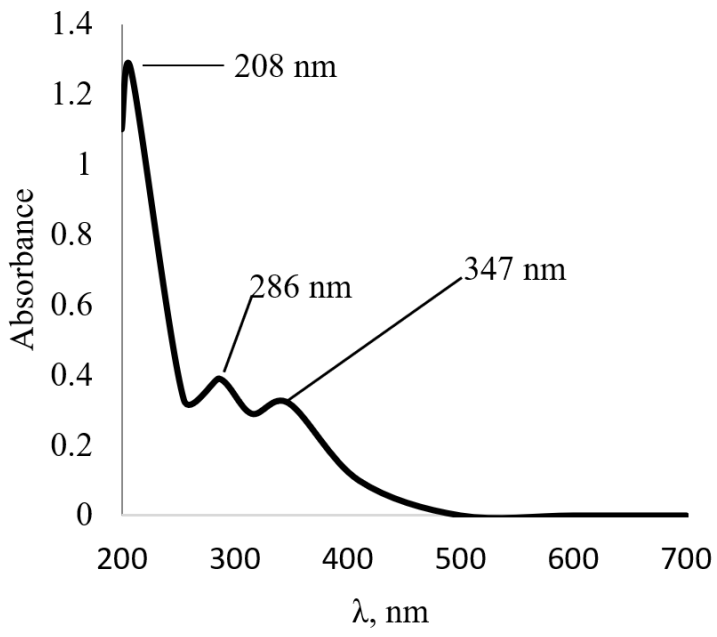

(b)

Figure 5. UV spectrum of the synthesized oligomer: (a) with instant addition of the condensing agent; (b) with smooth introduction of the condensing agent.

The UV spectrum of the second solution (Figure $5 b$ ), where the addition of the condensing agent was smooth and at a rate of $0.05 \mathrm{~mL} / \mathrm{min}$, shows absorption maxima at 208 and $286 \mathrm{~nm}$, which are not characteristic of 2-furyl methyl alcohol and 2-furaldehyde. It can be argued that the condensing agent completely entered into a condensation reaction with 1,3,5-trihydroxybenzene to form 1,3,5-trihydroxybenzene-2-furaldehyde oligomer. Thus, it was found that in the complete course of the condensation reaction between 1,3,5-trihydroxybenzene and the condensing agent, 2-furaldehyde, occurs with the gradual introduction of the agent into the reaction mixture which allows you to get a better product. It can be assumed that the sodium salt of 2-furancarboxylic acid, formed as a result of disproportionation of 2-furaldehyde, increases the rate of crosslinking of the obtained oligomers in solution, which greatly affects the storage time and efficiency of the water-reducing agent.

3.3. Study of the Product of the Interaction of 1,3,5-Trioxybenzene with 2-Furaldehyde in an Alkaline Medium by IR Spectroscopy

To interpret the IR spectrum of the product of the interaction of 1,3,5-trioxybenzene with 2-furaldehyde in an alkaline medium, the IR spectra of the starting monomers were obtained: 2-furaldehyde (Figure 6) and 1,3,5-trihydroxybenzene (Figure 7). 


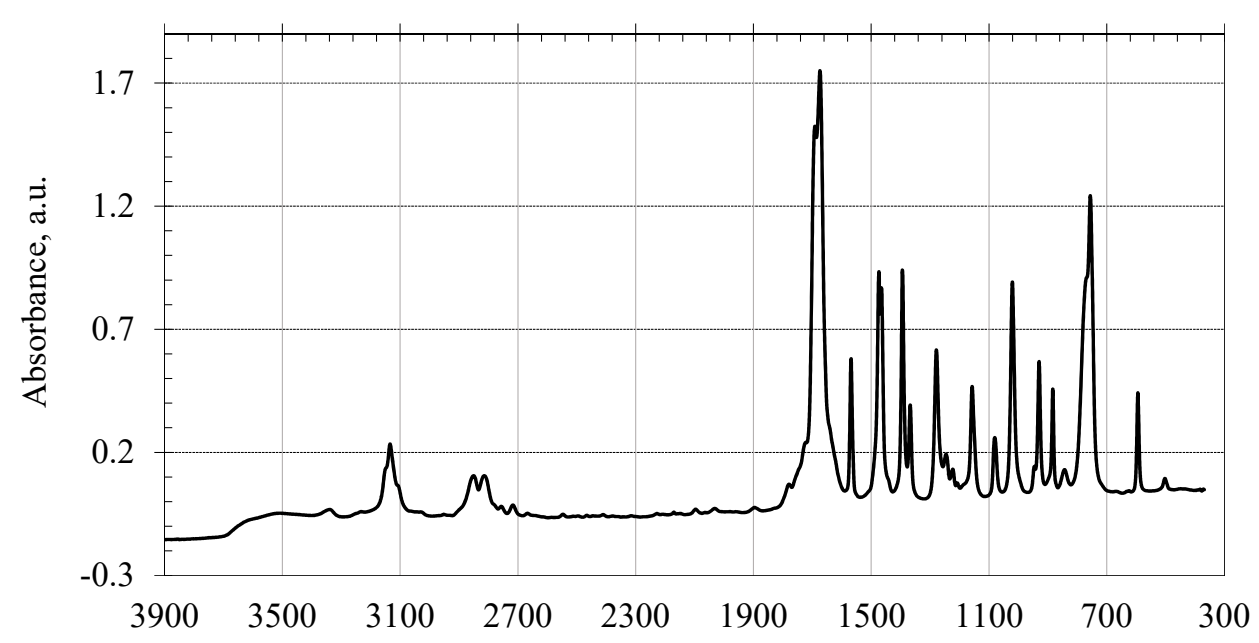

Wave number, $\mathrm{cm}^{-1}$

Figure 6. IR spectrum of 2-furaldehyde.

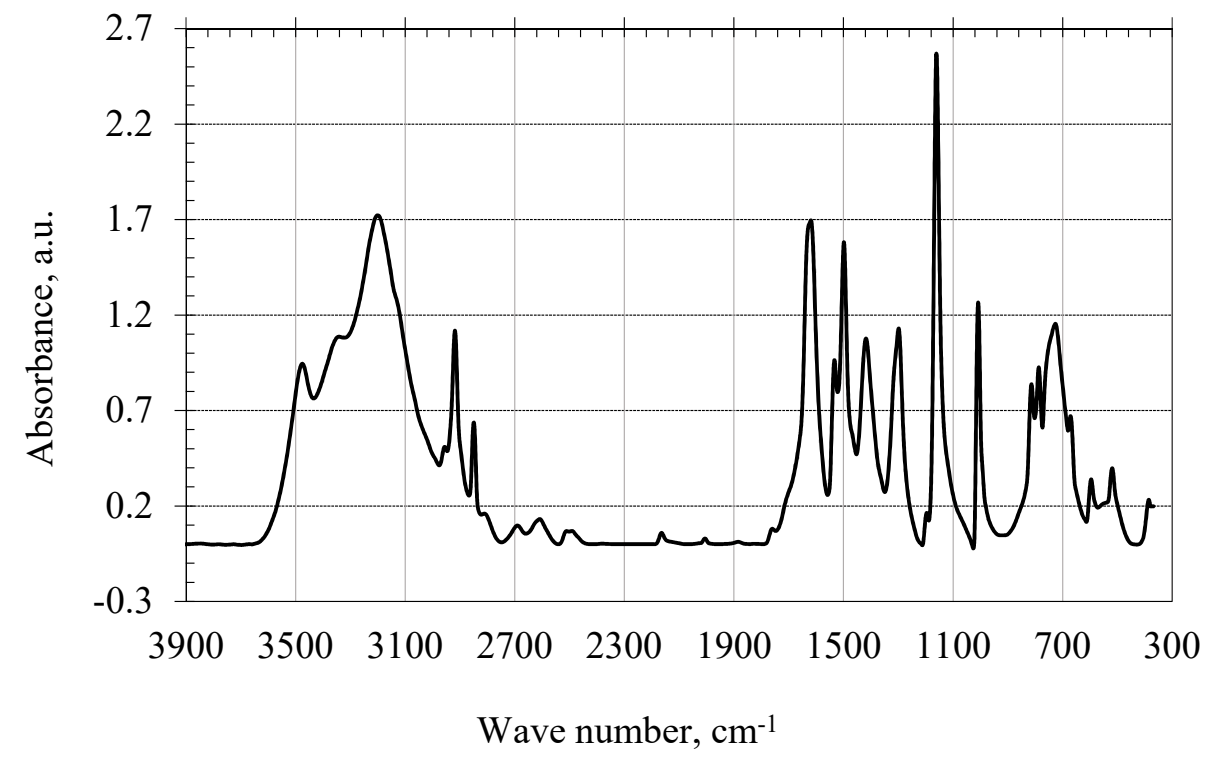

Figure 7. IR spectrum of 1,3,5-trihydroxybenzene.

The IR spectrum of 2-furaldehyde (Figure 6) exhibits weak stretching vibrations of the $\mathrm{C}-\mathrm{H}$ bond in the range of $3200-2800 \mathrm{~cm}^{-1}$, which are characteristic of heterocyclic compounds. Skeletal vibrations of the molecule are also observed in the region of $1800-900 \mathrm{~cm}^{-1}$, and in the region $1600-1900 \mathrm{~cm}^{-1}$ there are stretching vibrations of the $\mathrm{C}=\mathrm{O}$ group that characterize this compound.

The IR spectrum of 1,3,5-trihydroxybenzene (Figure 7) shows internal and intermolecular H-bonds in the range of $3500-3000 \mathrm{~cm}^{-1}$, which are characteristic of phenols. In the region of 3400-3100 $\mathrm{cm}^{-1}$, stretching vibrations of hydroxyl groups are observed, and in the region of $1900-1400 \mathrm{~cm}^{-1}$, composite frequencies and overtones are concentrated, which determine the type of substitution in the benzene nucleus. The strongest part of absorption is in the region 1200-1100 $\mathrm{cm}^{-1}$, which is responsible for in-plane deformation vibrations of $\mathrm{C}-\mathrm{H}$ bonds of 1,3-, 1,5-, 1,3,5-substituted positions. In a specific case, the IR spectrum corresponds to 1,3,5-substituted phenol.

The IR spectrum of the product of the interaction of 1,3,5-trioxybenzene with 2furaldehyde in an alkaline medium is shown in Figure 8. The IR spectrum of the obtained oligomer clearly shows absorption bands of weak stretching vibrations of $\mathrm{CH}$ bonds in 
aromatic compounds (this indicates the addition of $\mathrm{CH}$ bonds of the heterocyclic ring to the benzene ring). In the range of $2900-2200 \mathrm{~cm}^{-1}$, the stretching vibrations of hydroxyl groups weaken.

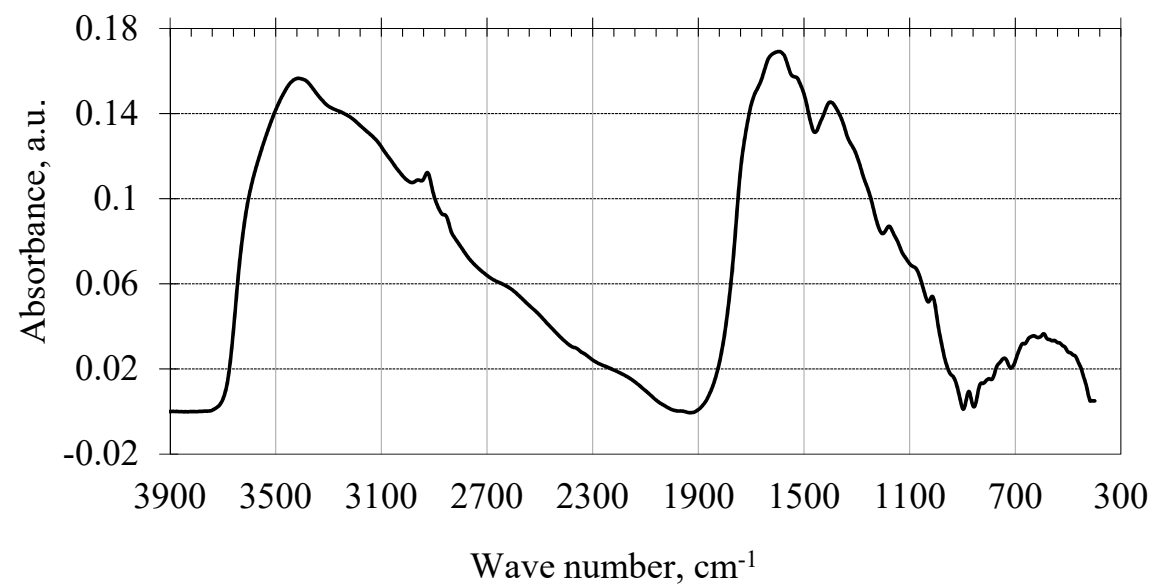

Figure 8. IR spectrum of the product of the interaction of 1,3,5-trioxybenzene with 2-furaldehyde in an alkaline medium.

Thus, as a result of the studies carried out, it was found that the condensation of 2-furaldehyde with 1,3,5-trihydroxybenzene in an alkaline medium forms a new substance1,3,5-trihydroxybenzene-2-furaldehyde oligomer, which is confirmed by the IR spectrum of the obtained product (Figure 8). In the IR spectrum of the product of the interaction of 1,3,5-trioxybenzene with 2-furaldehyde in an alkaline medium (Figure 8), stronger $\mathrm{C}-\mathrm{H}$ bonds appear, and stretching vibrations of the $\mathrm{C}=\mathrm{O}$ group are not observed.

3.4. Investigation of the Product of the Interaction of 1,3,5-Trioxybenzene with 2-Furaldehyde in an Alkaline Medium by HPLC Analysis

Figure 9 shows a liquid chromatogram of a mixture of 1,3,5-trioxybenzene and 2 furaldehyde in water (Figure 9a), as well as a liquid chromatogram of the products obtained by condensation interaction of 1,3,5-trioxybenzene with 2-furaldehyde in an alkaline medium (Figure 9b). HPLC analysis showed that the peak at 7 min corresponds to the yield of 1,3,5-trioxybenzene and the peak at 9 min corresponds to the yield of 2-furaldehyde (Figure 9a). The area of the peaks was used to calculate the relative concentration of 1,3,5-trioxybenzene and 2-furaldehyde at different time stages of the reaction. The chromatograms show that at the beginning of the co-condensation reaction of 1,3,5trioxybenzene with 2-furaldehyde in an alkaline medium, their mono derivatives are formed (peak 3 in Figure 9b). After 40-50 min (Figure 9c), a further change in the molecular structure occurs, as evidenced by a decrease in peak 3 (mono derivatives) and peak 1 (the remaining 1,3,5-trioxybenzene) and the appearance of peak 4 at $11 \mathrm{~min}$, corresponding to oligomeric molecules, which are better adsorbed on this sorbent and, therefore, leave the column later.

HPLC analysis showed that by the end of the reaction (after 90 min of synthesis), with the gradual introduction of a condensing agent, 1,3,5-trioxybenzene reacted in an amount of $70.0 \mathrm{wt} . \%$, and 2-furaldehyde in the amount of $97.0 \mathrm{wt} . \%$. 

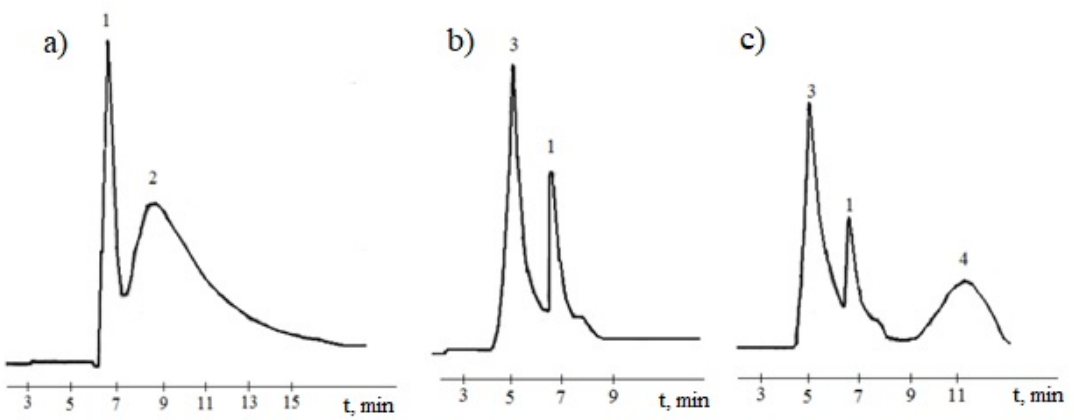

Figure 9. Liquid chromatogram of a mixture of 1,3,5-trioxybenzene and 2-furaldehyde in water (a) and the reaction mixture after $20 \mathrm{~min}(\mathbf{b})$ and $40 \mathrm{~min}$ (c): 1-peak of 1,3,5-trioxybenzene; 2-peak of 2-furaldehyde; 3-mono derivatives of phloroglucinol and furfural; 4-oligomers.

3.5. Study of the Product of the Interaction of 1,3,5-Trioxybenzene with 2-Furaldehyde in an Alkaline Medium by NMR Spectroscopy

Figure 10 shows the ${ }^{1} \mathrm{H}-\mathrm{NMR}$ spectrum of a mechanical mixture of 1,3,5-trioxybenzene and 2-furaldehyde, as well as the reaction product obtained by condensation reaction of 1,3,5-trioxybenzene with 2-furaldehyde in an alkaline medium.

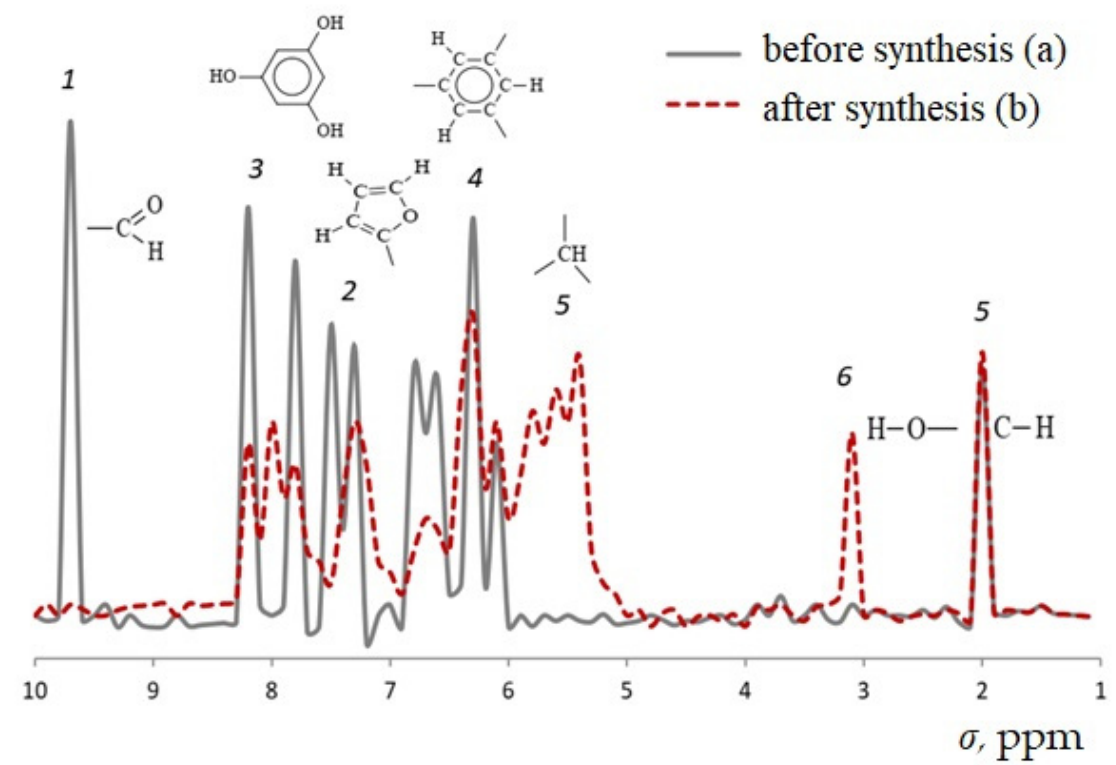

Figure 10. ${ }^{1} \mathrm{H}-\mathrm{NMR}$ spectra (a) a mechanical mixture of 1,3,5-trioxybenzene and 2-furaldehyde; (b) the product of the interaction of 1,3,5-trioxybenzene with 2-furaldehyde in an alkaline medium: 1-protons of the aldehyde group of 2-furaldehyde; 2-protons of the furan ring; 3-protons of $\mathrm{OH}$ groups of 1,3,5-trioxybenzene; 4-protons of aromatic rings of 1,3,5-trioxybenzene; 5-methine protons $(\mathrm{CH}) ; 6-\mathrm{OH}$ groups.

On the ${ }^{1} \mathrm{H}-\mathrm{NMR}$ spectrum of a mechanical mixture of 1,3,5-trioxybenzene and 2furaldehyde (Figure 10a) in the range of 9-10 ppm there is a peak formed as a result of the resonance of aldehyde protons of 2-furaldehyde (1). In the course of the condensation reaction, by taking the integral curves, the dependence of the area of this peak on the reaction time was determined. The change in area corresponds to a change in the relative concentration of the aldehyde proton in the reaction mixture.

Studies of ${ }^{1} \mathrm{H}-\mathrm{NMR}$ spectra of condensation products at certain time intervals showed that as a result of the reaction, the signal of 9.0-10.0 ppm gradually disappears, corresponding to the protons of the aldehyde group of 2-furaldehyde, and a new peak appears in the region of $3.0 \mathrm{ppm}$, indicating about the formation of-C-OH-groups $(5,6)$ (Figure 10b). A decrease in the signals of aromatic protons of 5.5-5.8 ppm (4) indicates the binding 
of molecules into oligomers and a decrease in the degree of mobility of the remaining protons. With condensation, the shape of the peak in the range of 8.0-8.3 ppm changed, corresponding to the protons of the -OH groups of 1,3,5-trioxybenzene, its splitting was observed, which corresponds to a change in the influence of neighboring protons as a result of the appearance of additional substituents in aromatic rings 1,3,5-trioxybenzene with the formation of bonds (6), and subsequently (5).

Comparative analysis of integral curves of the $1 \mathrm{H}-\mathrm{NMR}$ spectrum the product of the reaction of 1,3,5-trioxybenzene with 2-furaldehyde in an alkaline medium gave the following ratio of protons-protons of 1,3,5-trioxybenzene rings and 2-furaldehyde: $\mathrm{OH}$ group protons: $\mathrm{CH}$-group protons $\approx 1.5: 2.5: 1$. This made it possible to determine the most probable oligomer molecule.

The scheme of the joint condensation of 1,3,5-trioxybenzene with 2-furaldehyde in an alkaline medium with the formation of oligomers is shown in Figure 11.

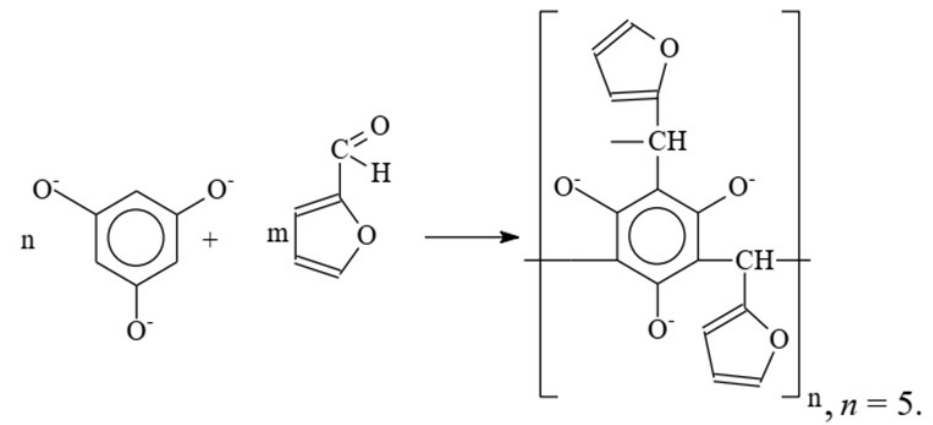

Figure 11. Scheme of the joint condensation of 1,3,5-trioxybenzene with 2-furaldehyde in an alkaline medium.

The yield of the reaction product was calculated using the formula (2). When calculating the "Actual Yield" value, the quantitative data of the reacted substances were taken into account. According to HPLC analysis, 1,3,5-trioxybenzene reacted in the amount of $70.0 \mathrm{wt} . \%$, and 2-furaldehyde in the amount of $97.0 \mathrm{wt} . \%$. Thus, the yield of 1,3,5-trihydroxybenzene-2-furaldehyde oligomer was $89.2 \mathrm{wt} . \%$. The average molecular weight of 1,3,5-trihydroxybenzene-2-furaldehyde oligomer calculated by the Rast method is $1200 \pm 30$.

\subsection{Determination of the Plasticizing Ability of 1,3,5-Trihydroxybenzene-2-furaldehyde Oligomer}

Determination of the plasticizing ability of 1,3,5-trihydroxybenzene-2-furaldehyde oligomer and its optimal dosage was carried out by determining the diameter of the minicone spread according to the method developed at the Scientific Research, Design and Technological Institute of Concrete and Reinforced Concrete named after A. A. Gvozdev in Russia. The process for determining the plasticizing ability is shown schematically in Figure 12. The cement paste is loaded into a mini-cone, then it is raised and the diameter of the spreading mixture is measured.

A series of cement pastes with the addition of the investigated plasticizing additive in the amount of $0.1 ; 0.2 ; 0.3 ; 0.4 \%$ by weight of cement (calculated on dry matter) were prepared. In this case, the water-cement ratio in all experiments was the same 0.4 . Figure 13 shows the data of the dependence of the diameter of the mini-cone spreading on the dosage of 1,3,5-trihydroxybenzene-2-furaldehyde.

Analysis of the data presented in Figure 13 showed that the diameter of the spreading of the cement paste of the unplasticized system (without the addition of a plasticizing additive) is $4.5 \mathrm{~cm}$. In the presence of the additive, a significant dilution of the cement paste is observed. An increase in the spreading diameter of the mini-cone of the plasticized system of up to $19 \mathrm{~cm}$ determines the value of the plasticizing ability of the synthesized oligomer. The minimum dosage of 1,3,5-trihydroxybenzene-2-furaldehyde at which the 
maximum plasticizing effect is achieved is $0.3 \%$ of the cement mass, which characterizes the plasticizing activity of the additive. Thus, the optimal dosage of the developed plasticizing additive is $0.3 \%$ of the cement weight (calculated on dry matter).
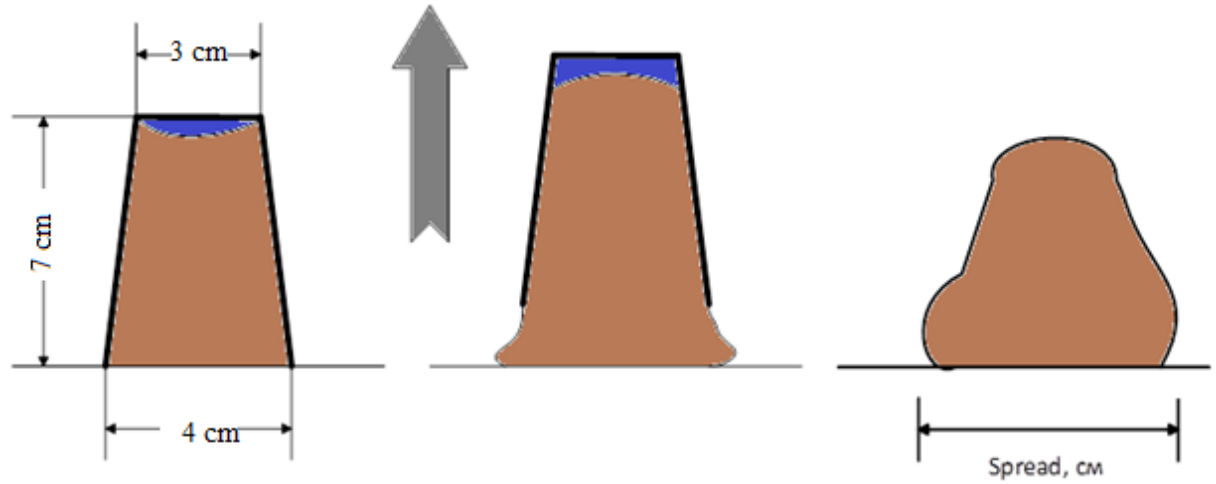

Figure 12. Schematic process for determining the plasticizing ability of additives for cement systems.

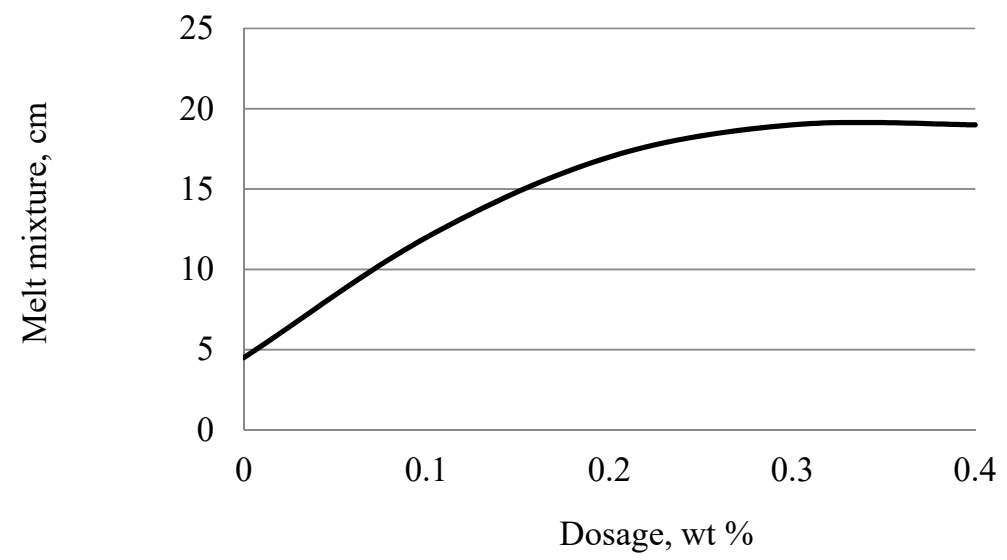

Figure 13. Dependence of the diameter of the mini-cone spreading on the dosage of 1,3,5trihydroxybenzene-2-furaldehyde.

Table 1 presents data on the mechanical characteristics of cement compositions using 1,3,5-trihydroxybenzene-2-furaldehyde additives.

Table 1. Mechanical characteristics of cement compositions using 1,3,5-trihydroxybenzene-2-furaldehyde additive.

\begin{tabular}{cccc}
\hline $\begin{array}{c}\text { Content of Plasticizing } \\
\text { Additive, \% }\end{array}$ & Water-Cement Ratio & $\begin{array}{c}\text { Mini-Cone Spreading } \\
\text { Diameter, cm }\end{array}$ & $\begin{array}{c}\text { Compressive Strength 28 } \\
\text { Days, MPa }\end{array}$ \\
\hline- & 0.4 & 4.5 & 58.6 \\
0.3 & 0.4 & 19 & 58.2 \\
0.3 & 0.3 & 10 & 67.5 \\
0.3 & 0.45 & 20 & 56.2 \\
\hline
\end{tabular}

Analysis of the data in Table 1 showed that the use of the developed plasticizing additive of 1,3,5-trihydroxybenzene-2-furaldehyde in an amount of $0.3 \%$ (by weight of dry matter) can significantly reduce the water-cement ratio while maintaining increased mobility and obtaining increased strength characteristics of cement compositions. In addition, the results obtained show the possibility of using the synthesized additive to obtain SCC. 


\section{Conclusions}

The paper presents the possibility of synthesizing a plasticizing additive based on 2 -furaldehyde and 1,3,5-trihydroxybenzene, and also presents the chemistry of the reaction between the components.

It was found that 1,3,5-trihydroxybenzene does not react with $\mathrm{NaOH}$, while 2-furaldehyde reacts with $\mathrm{NaOH}$ to form two products. The characteristic absorption maximum at a wavelength of $245 \mathrm{~nm}$ corresponds to 2-furancarboxylic acid and its salt, and the characteristic absorption maximum at a wavelength of $216 \mathrm{~nm}$ corresponds to 2-furyl methyl alcohol.

As a result of the work, it was revealed that to obtain 1,3,5-trihydroxybenzene-2furaldehyde oligomer, a gradual introduction of a condensing agent (2-furaldehyde) at a rate of $0.05 \mathrm{~mL} / \mathrm{min}$ is required. With the instant addition of a condensing agent, absorption maxima are observed in the region of 215 and $279 \mathrm{~nm}$, which are characteristic of 2-furyl methyl alcohol and 2-furaldehyde, respectively. This indicates that the condensing agent did not completely enter into a condensation reaction with 1,3,5-trihydroxybenzene, and began to partially disproportionate with the formation of 2-furylmethyl alcohol.

Comparative analysis of integral curves of the ${ }^{1} \mathrm{H}-\mathrm{NMR}$ spectrum the product of the reaction of 1,3,5-trioxybenzene with 2-furaldehyde in an alkaline medium gave the following ratio of protons-protons of 1,3,5-trioxybenzene rings and 2-furaldehyde: $\mathrm{OH}$ group protons: $\mathrm{CH}$-group protons $\approx 1.5: 2.5: 1$.

The optimal dosage of the developed plasticizing additive is $0.3 \%$ of the cement weight (calculated on dry matter). The developed plasticizing additive can significantly reduce the water-cement ratio while maintaining increased mobility and obtaining increased strength characteristics of cement compositions.

Author Contributions: Conceptualization, V.A.P. and S.A.S.; methodology, validation, V.A.P. and N.I.C.; formal analysis, N.I.C.; investigation, D.S.R.; writing-original draft preparation, N.I.C.; writing-review and editing, S.A.S.; supervision, N.I.C.; funding acquisition, N.I.C. All authors have read and agreed to the published version of the manuscript.

Funding: The work is realized using equipment of High Technology Center at BSTU named after V.G. Shukhov the framework of the State Assignment of the Ministry of Education and Science of the Russian Federation, project No. FZWN-2021-0015.

Conflicts of Interest: The authors declare no conflict of interest. The funders had no role in the design of the study; in the collection, analyses, or interpretation of data; in the writing of the manuscript, or in the decision to publish the results.

\section{References}

1. Mazurok, P.; Turgunov, T.; Svidersky, V.; Tokarchuk, V. Oil Well Cement Additives: A Review of the Common Types. Oil Gas Res. 2016, 2, 112.

2. Svintsov, A.P.; Shchesnyak, E.L.; Galishnikova, V.V.; Fediuk, R.S.; Stashevskaya, N.A. Effect of nano-modified additives on properties of concrete mixtures during winter season. Constr. Build. Mater. 2020, 237, 117527. [CrossRef]

3. Shi, J.; Fan, W.; Lin, Y.; Zhao, P.; Ouyang, J. Effects of Surfactant Warm-Mix Additives on the Rheological Properties of HighViscosity Asphalt. Adv. Mater. Sci. Eng. 2020, 2020, 6506938. [CrossRef]

4. Zhang, S.; Qiao, W.; Li, Y.; Xi, K.; Chen, P. Effect of Additives on the Rheological and Mechanical Properties of Micro-fine-CementBased Grout. Adv. Mater. Sci. Eng. 2019, 2019, 1931453. [CrossRef]

5. Frą, M.; Szudek, W.; Szołdra, P.; Pichór, W. The applicability of shungite as an electrically conductive additive in cement composites. J. Build. Eng. 2021, 45, 103469. [CrossRef]

6. Konkol, J. Fracture Toughness and Fracture Surface Morphology of Concretes Modified with Selected Additives of Pozzolanic Properties. Buildings 2019, 9, 174. [CrossRef]

7. Pavon, C.; Aldas, M.; López-Martínez, J.; Ferrándiz, S. New Materials for 3D-Printing Based on Polycaprolactone with Gum Rosin and Beeswax as Additives. Polymers 2020, 12, 334. [CrossRef]

8. Breilly, D.; Fadlallah, S.; Froidevaux, V.; Colas, A.; Allais, F. Origin and industrial applications of lignosulfonates with a focus on their use as superplasticizers in concrete. Constr. Build. Mater. 2021, 301, 124065. [CrossRef]

9. Zhang, Z.; Li, Y.; Ren, L.; Guo, Z.; Jiang, H.; Liu, N. Evaluation of Rheological Parameters of Slag-Based Paste Backfill with Superplasticizer. Adv. Mater. Sci. Eng. 2021, 2021, 6673033. [CrossRef]

10. Papo, A.; Piani, L.; Ricceri, R. Rheological Properties of Very High-Strength Portland Cement Pastes: Influence of Very Effective Superplasticizers. Int. J. Chem. Eng. 2010, 2010, 682914. [CrossRef] 
11. Gupta, N.; Gupta, A.; Saxena, K.K.; Shukla, A.; Goyal, S.K. Mechanical and durability properties of geopolymer concrete composite at varying superplasticizer dosage. Mater. Today Proc. 2020, 44, 12-16. [CrossRef]

12. Chakkamalayath, J.; Santhanam, M.; Gettu, R. Cement-superplasticiser compatibility-Issues and challenges. Indian Concr. J. 2021, 85, 48-60.

13. Wu, Y.; Li, Q.; Li, G.; Tang, S.; Niu, M.; Wu, Y. Effect of Naphthalene-Based Superplasticizer and Polycarboxylic Acid Superplasticizer on the Properties of Sulfoaluminate Cement. Materials 2021, 14, 662. [CrossRef]

14. Coppola, L.; Lorenzi, S.; Kara, P.; Garlati, S. Performance and Compatibility of Phosphonate-Based Superplasticizers for Concrete. Buildings 2017, 7, 62. [CrossRef]

15. Hekal, E.E.; Kishar, E.A. Effect of sodium salt of naphthalene-formaldehyde polycondensate on ettringite formation. Cem. Concr. Res. 1999, 29, 1535-1540. [CrossRef]

16. Wang, H.; Yang, X.; Xiong, W.; Liu, X.; Zhang, Z. Synthesis and the Effects of New Melamine Superplasticizer on the Properties of Concrete. ISRN Chem. Eng. 2013, 2013, 708063. [CrossRef]

17. Essam, A.; Ahmed, D.A.E.M.; Hegazy, W.S. Hydration reactions of the system C3A-CaSO4.2H2O (1:1 mole ratio) at 30 and $50{ }^{\circ} \mathrm{C}$. Part II: Effect of naphthalene formaldehyde sulfonate. Adv. Cem. Res. 2011, 23, 123-128. [CrossRef]

18. Chen, S.; Zhang, J.; Sun, S.; Zhong, K.; Shao, Q.; Xu, H.; Huang, H.; Wei, J. Dispersion, fluidity retention and retardation effect of polyacrylate-based ether superplasticizer nanomicelles in Portland cement. Constr. Build. Mater. 2021, 290, 123149. [CrossRef]

19. Zhang, R.; Li, Q.; Zhang, A.; Liu, Y.; Lei, J. The synthesis technique of polyacrylic acid superplasticizer. J. Wuhan Univ. Technol. Sci. Ed. 2008, 23, 830-833. [CrossRef]

20. Lin, X.; Pang, H.; Wei, D.; Lu, M.; Liao, B. Effect of superplasticizers with different anchor groups on the properties of cementitious systems. Colloids Surf. A Physicochem. Eng. Asp. 2021, 630, 127207. [CrossRef]

21. Tian, H.; Kong, X.; Su, T.; Wang, D. Comparative study of two PCE superplasticizers with varied charge density in Portland cement and sulfoaluminate cement systems. Cem. Concr. Res. 2018, 115, 43-58. [CrossRef]

22. Stecher, J.; Plank, J. Novel concrete superplasticizers based on phosphate esters. Cem. Concr. Res. 2019, 119, 36-43. [CrossRef]

23. Xiang, S.; Gao, Y.; Shi, C. Progresses in Synthesis of Polycarboxylate Superplasticizer. Adv. Civ. Eng. 2020, $2020,8810443$. [CrossRef]

24. Dalas, F.; Pourchet, S.; Nonat, A.; Rinaldi, D.; Sabio, S.; Mosquet, M. Fluidizing efficiency of comb-like superplasticizers: The effect of the anionic function, the side chain length and the grafting degree. Cem. Concr. Res. 2015, 71, 115-123. [CrossRef]

25. Ren, Q.; Zou, H.; Liang, M.; Wang, Y.; Wang, J. Preparation and characterization of amphoteric polycarboxylate and the hydration mechanism study used in portland cement. RSC Adv. 2014, 4, 44018-44025. [CrossRef]

26. Akhlaghi, O.; Menceloglu, Y.Z.; Akbulut, O. Poly(carboxylate ether)-based superplasticizer achieves workability retention in calcium aluminate cement. Sci. Rep. 2017, 7, 201-224. [CrossRef]

27. Zhu, J.; Hui, J.; Luo, H.; Zhang, B.; Wei, X.; Wang, F.; Li, Y. Effects of polycarboxylate superplasticizer on rheological properties and early hydration of natural hydraulic lime. Cem. Concr. Compos. 2021, 122, 104052. [CrossRef]

28. Boota, M.; Parans Paranthaman, M.; Naskar, A.K.; Li, Y.; Akato, K.; Gogotsi, Y. Waste Tire Derived Carbon-Polymer Com-posite Paper as Pseudocapacitive Electrode with Long Cycle Life. ChemSusChem 2015, 12, 43-66.

29. Bond, J.Q.; Upadhye, A.A.; Olcay, H.; Tompsett, G.A.; Jae, J.; Xing, R. Synthesis of Furfural from Water Hyacinth (Eichornia croassipes). IOP Conf. Ser. Mater. Sci. Eng. 2014, 7, 1500-1523.

30. Mukherjee, A.; Portillo-Perez, G.; Dumont, M.J. Synthesis of hydroxymethylfurfural and furfural from hardwood and soft-wood pulp using ferric sulphate as catalyst. Front. Chem. Sci. Eng. 2019, 13, 531-542. [CrossRef]

31. Poluektova, V.A.; Kozhanova, E.P.; Kudina, A.E. Adsorption of phloroglucinfurfural oligomers on the surface of polymer mineral dispersions. Bull. Belgorod State Technol. Univ. 2017, 10, 116-122.

32. Roselli, A.; Carvalho, Y.; Dumeignil, F.; Cavani, F.; Paul, S.; Wojcieszak, R. Liquid Phase Furfural Oxidation under Un-controlled $\mathrm{pH}$ in Batch and Flow Conditions: The Role of In Situ Formed Base. Catalysts 2020, 10, 73. [CrossRef]

33. Kenzo, H. Handbook of Ultraviolet and Visible Absorption Spectra of Organic Compounds; Plenum Press Data Division: New York, NY, USA, 1967; 642p. 